\title{
LA PROHIBICIÓN DEL PRINCIPIO DE OPORTUNIDAD EN LOS DELITOS CONTRA LA ADMINISTRACIÓN PÚBLICA COMETIDOSPOR FUNCIONARIOS
}

\section{THE PROHIBITION OF THE PRINCIPLE OF OPPORTUNITY IN CRIMES AGAINST THE PUBLIC ADMINISTRATION COMMITTED BY OFFICIALS}

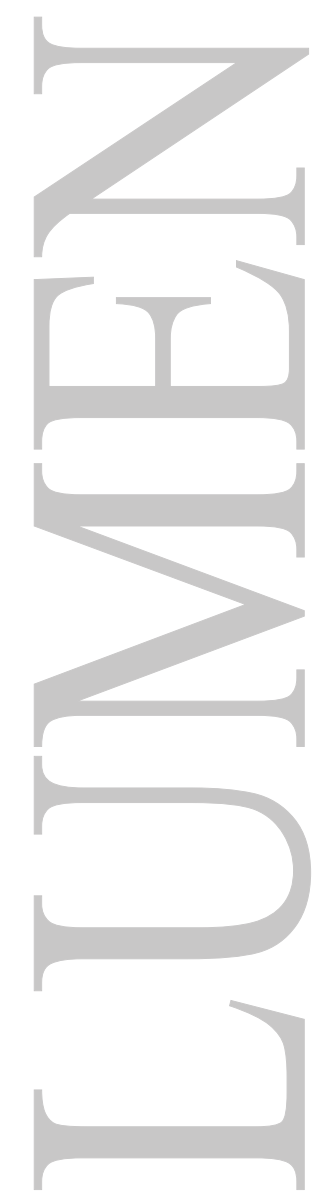




\title{
LA PROHIBICIÓN DEL PRINCIPIO DE OPORTUNIDAD EN LOS DELITOS CONTRA LA ADMINISTRACIÓN PÚBLICA COMETIDOS POR FUNCIONARIOS
}

\author{
THE PROHIBITION OF THE PRINCIPLE OF OPPORTUNITY \\ IN CRIMES AGAINST THE PUBLIC ADMINISTRATION COMMITTED BY OFFICIALS
}

Omar Pezo Jimenez

\begin{abstract}
RESUMEN
Las implicancias de la prohibición del principio de oportunidad en los casos de los delitos de peculado culposo, es una investigación del tipo aplicada que busco dar una propuesta de solución en relación a una norma prohibitiva del Código Procesal Penal que afecta gravemente nuestro sistema procesal generando carga procesal en nuestras instituciones pública e impidiendo en pago de la reparación civil de forma célere, de esta manera se llegó a conocer de manera científica datos reveladores sobre la carga procesal en los delitos de corrupción de funcionarios y más aun de la celeridad del pago de las reparaciones civiles a favor del Estado, siendo muy alarmante los números generados, por diversos factores mencionados en la presente tesis.
\end{abstract}

\section{PALABRAS CLAVE}

Peculado, corrupción, delito, Principio de oportunidad, delitos contra la administración pública, reparación civil, bien jurídico, política criminal.

\begin{abstract}
The implications of the prohibition of the principle of opportunity in Cases of Crimes of culpable peculation , is a research type applied to seek Give a proposed solution in relation to a prohibitory rule of the Criminal Procedure Code that seriously affects our judicial system Generating load procedure in Our public institutions and by preventing payment of civil damages so fast, way is I get to know scientifically important information about the procedural burden on Crimes of Corruption of public Officials and even more so on the speed of the payment of Civil repairs State a favor, very alarming being generated numbers for various factors mentioned in this thesis
\end{abstract}

\section{KEY WORDS}

Embezzlement, corruption, crime, principle of opportunity, crimes against public administration, civil damages, the legal, criminal policy

\section{INTRODUCCIÓN:}

En la actualidad en el Perú nos encontramos frente a un fenómeno delincuencial muy difícil de frenar, llamado corrupción, con el transcurso de los años el Estado está sumando esfuerzos, para combatir este mal como son las fiscalías especializada en delitos de corrupción, las Procuraduría Publicas Anticorrupción y los juzgados Especializados en delitos de corrupción, pero todo ello es poco frente a la gran carga procesal que significan estos tipos de delitos, sumados a la complejidad de los mismos y la poca especialización por parte de los operadores del derecho, siendo así debe tomarse todas las medidas posibles para disminuir dicha carga, en el artículo 2 del Código Procesal Penal peruano está amparado el principio de oportunidad, pero en el mismo artículo también se encuentra prohibido para los funcionarios públicos, restringiéndose la posibilidad de que los delitos contra la administración pública sean susceptibles al principio de oportunidad, lo cual en la actualidad genera carga procesal y disminuye la efectivización de la reparación civil. 
En los objetivos se busca Determinar si la prohibición del principio de oportunidad en los Delitos de Peculado Culposo incide significativamente en la congestionada carga procesal de la Fiscalía Especializada en Delitos de Corrupción de Funcionarios y la Procuraduría Publica Anticorrupción, impidiendo el pago de la reparación civil de forma célere, y para ello se debe establecer si los casos de peculado culposo inciden significativamente en la congestionada carga procesal de la Fiscalía Especializada en Delitos de Corrupción de Funcionarios y la Procuraduría Publica Anticorrupción, además se debe precisar si el uso salidas y mecanismos alternativos de solución de conflictos penales en los delitos contra la administración pública, estimula el pago de la reparación civil a favor del Estado de forma célere, en la Procuraduría Publica Anticorrupción.

\section{CONTENIDO}

\section{BASES DEL PRINCIPIO DE OPORTUNIDAD}

Uno de los más grandes problemas fundamentales que aqueja los ordenamientos jurídicos, es el congestionamiento de los procesos penales en la administración de justicia, que acarrea muchos problemas consigo, como es la lentitud de los procesos, el cobro tardío de las reparaciones civiles, prescripción de los delitos, desaparición de pruebas fundamentales, todos ellos que simplemente generan impunidad, afectando gravemente no solo a los imputados y a las víctimas, si no a la sociedad por ser el Derecho Penal, un derecho público.

Siguiendo los lineamientos de Bacigalupo (1987) "La política criminal de los ilícitos menores (o de los que escapan al ámbito de interés social o público) requiere contemplar el problema desde la doble perspectiva del Derecho penal material y Derecho procesal penal: la política criminal también se hace mediante Derecho procesal" (p. 27)

En ese seguir de problemáticas que causan los delitos menores es que nace el principio de oportunidad como una posibilidad de mejora a la política criminal, de una modificación puramente procesal para poder quebrar la inflexibilidad de la legalidad, creando beneficios para el imputado, la víctima, la sociedad en su conjunto y el sistema de justicia, es decir el Estado como ente que cuenta con el lusPunendi. Es necesario mencionar lo dicho por Prado (1990) en la época de inicios de los años noventa "Los desarrollos de la política general de distintos gobiernos han sido semejantes. Los problemas de la inseguridad ciudadana, de la inoperancia de los órganos de control y del recurso permanente a un Derecho penal simbólico, no han sido superados" (p. 84) Es claro decir que los órganos de control pertenecientes a la criminalización secundaria no han funcionado correctamente, y esto no ha cambiado pero se debe señalar que tras la aparición de los mecanismos alternativos de solución de conflicto ha existido una mejora considerable en el tratamiento de los delitos en nuestro país, muy difícil de negar.

Pues no es una novedad que el Derecho Penal por medio del Estado le es casi imposible juzgar los delitos de poca monta, dejando impunidad tras su paso, lo cual es casi inaceptable en un Estado de Derecho garantista como apunta a ser los grandes Estados, Catacora (1996) "Resultando ineficaz la respuesta tradicional frente al delito mediante la norma procesal, es preferible buscar otras alternativas más prácticas, cuando el hecho no afecte gravemente el interés público" (p. 187) nos expresa en este punto el resultado ineficaz de la Legalidad la cual es la más común respuesta frente a un hecho delictivo, pero no es siempre la que mejor solución traiga, cabe mencionar que el autor agrega el interés público y su poca afectación que debe contener este.

\section{ANTECEDENTES HISTÓRICOS}

Para poder hablar del origen del principio de oportunidad, es necesario comprender el origen del principio de legalidad el cual aparece desde las primeras ideas filosóficas de Estado, igualdad y 
democracia del Barón de Montesquieu y Jean Jacques Rousseau como reacción a la arbitrariedad, el abuso de poder y la inseguridad jurídica de la época; Pero su real y verdadero enunciado aparece por primera vez en el libro Tratado de los delitos y las penas de Cesare Beccaria del año 1764, en el que en el capítulo tres nos dice: "Solo las leyes pueden decretar las penas de los delitos y esta autoridad debe residir únicamente en el Legislador que representa a toda la sociedad unida por el contrato social" (p. 21) Siendo esto reafirmado por la frase en latín "Nullum crimen, nulla poena sine previa lege"1 la cual es desarrollada por Paul Johann Anselm Von Feuerbach como parte del "Código de Baviera de 1813"2, de esta manera desde esa época con el principio de legalidad se creía que el Poder Legislativo era incapaz de cometer errores y dicha idea se mantuvo por los siguientes ciento cincuenta años, siendo de estricto uso el principio de legalidad frente a un hecho delictual, sin excepción alguna.

Bajo lo ya antes mencionado el principio de oportunidad surge como una respuesta al principio de legalidad, pues este no podía responder a todos los delitos y más aun con los delitos de bagatela o menudeo que resultaban ser gran parte de la carga procesal, de esta manera el Estado vio que el Sistema jurídico no respondía a los lineamientos actuales en cuanto a un control punitivo eficaz y oportuno. De esta manera se debían crear sistemas de simplificación procesal que permitan corregir los excesos procesales, permitiendo no solo dar eficacia y celeridad al sistema, sino llegar a una solución satisfactoria para todas las partes, pues los delitos de poca relevancia jurídica constituían gran parte de los procesos penales de la época.

Es así que con el transcurso de los años la institución del principio de oportunidad alcanza su mayor auge de desarrollo en el sistema angloamericano con los denominados Prosecutorial Discretion o llamada discreción en la persecución y el Plea Bargaining o también llamada negociación, que son bases del sistema de persecución norteamericano, bajo este sistema los fiscales gozan de una absoluta discrecionalidad o como nos dice Gongora Mera: "pueden abstenerse a acusar aun cuando haya alta probabilidad de que el acusado cometió el delito y también pueden negociar con su pena sin sujeción a limitaciones y el juez solo decide sobre los términos de la negociación”.

A su vez se empezó a desarrollar el principio de oportunidad en Alemania a través de la Ley Emminger $^{3}$ del 04 de Enero de 1924, en el cual el Ministerio Publico queda facultado a abstenerse del ejercicio de la acción penal para satisfacción de determinados presupuestos como son el repara el daño, otorgar prestaciones de utilidad pública y cumplir determinadas obligaciones, años después en dicho país se denominó "Sistema oportuno reglado" en el cual se establece que la regla general es el principio de legalidad y la excepción el de oportunidad.

Como un punto trascendente Nereu Jose, Giacomolli (2012) se debe menciona lo señalado por el Comité de Ministros del Consejo Europeo en 21 de mayo del año 1975 "señalo: que no habría que excluir la posibilidad de recurrir a un proceso simplificado, en caso de infracciones menores" ( $p$. 55 ) tal vez este es uno de los primeros pasos que se dio en la actualidad para crear los mecanismos alternativos de solución de conflictos que en la actualidad conocemos, específicamente el principio de oportunidad.

Nereu (2012) En Europa se daba a mediados de los ochenta específicamente en el año 1986 la Reunión de Helsinki en el que sus principales conclusiones fueron:

a) El Ministerio Publico o "prosecutor" debe tener posibilidades de abstenerse de acusar en base a ciertas condiciones que vinculen al imputado de una infracción.

Ningún Delito, Ninguna pena sin ley previa

Obra cúspide de Johann Anselm Von Feuerbach, Es el código Penal del Estado Alemán de Baviera que sirvió como modelo para código penales tanto Europeos como Latinoamericanos.

3 Primera norma de carácter legislativo que desarrolla procedimientos de oportunidad para cesar la acción penal. 
b) Deben desarrollarse normas legislativas o administrativas en orden a la fijación de las condiciones que puedan ser impuestas en la decisión de abstención.

c) El objetivo principal de esas condiciones debe ser la mejora del comportamiento infractor y la compensación a la víctima de la infracción.

d) Las condiciones impuestas no deben restringir los derechos políticos del imputado ni deben tener naturaleza punitiva.

e) Las condiciones que pueden ir asociadas a una abstención deben ser similares a las que pueden ser impuesta en el cuadro de una condena condicional o una suspensión de la condena.

f) Particularmente en el caso de infracciones relacionadas al uso de drogas o de alcohol, debe ser considerada como una condición la posibilidad de sujeción a tratamiento médico o sumisión de vigilancia.

Todo esto es una clara manifestación que Europa tuvo a favor del principio de oportunidad en eso años, se buscaba regularizar un cierto pode muy diferente a los sistemas expresados en Estados Unidos en aquella época.

Posterior a ello a finales de los años ochenta e inicios de los noventa los movimientos de reformas procesales penales tomaron auge en Latinoamérica, todo esto en conjunción al Código Procesal Modelo para Iberoamérica del año 19894, específicamente en el artículo 230 que se hace mención al principio de oportunidad, en el que textualmente dice:

"Art 230. Oportunidad. En los casos en que la ley pena permita la aplicación de criterios de oportunidad para evitar la promoción de la persecución penal o para hacerla cesar, el Ministerio Público, por intermedio del funcionario que la ley orgánica determine, pedirá el archivo al juez de instrucción competente, quien decidirá sin recurso alguno. El tribunal podrá requerir la opinión del Ministerio Público sobre la cuestión, cuando lo considere conveniente. El archivo no supone la clausura definitiva de la persecución penal, que podrá ser reiniciada por el Ministerio Público cuando lo considere conveniente, salvo que la ley penal le otorgue otros efectos.

Los criterios de oportunidad deben ser fijados por la ley penal, pues representan soluciones normativas materiales para el ejercicio de la persecución penal; sin embargo, podría ocurrir que, según las disposiciones jurídicas relativas a la distribución de competencia legislativa de un Estado la mayoría de loa veces constitucionales; La fijación de estos criterios estuviera atribuida con exclusividad al legislador procesal. Se incluye, a continuación, un ejemplo posible sobre criterios de oportunidad.

"En las acciones que deben ser ejercidos por el Ministerio Público, él, con el consentimiento del juez competente, podrá decidir la clausura del procedimiento, en los siguientes casos:

1. Cuando se tratare de hechos que por su insignificancia o su falta de frecuencia, no afecten gravemente el interés público, salvo cuando la pena mínima supere los tres años de privación de libertad o el delito haya sido cometido por un funcionario público en ejercicio de su cargo.

2. Cuando la contribución o la culpabilidad del agente en la comisión del hecho sea leve y no exista ningún interés público gravemente comprometido en su persecución, salvo que se tratare de un delito cometido por un funcionario público en ejercicio de su cargo.

3. Cuando se tratare de casos que reúnen los presupuestos bajo los cuales el tribunal puede prescindir de la pena.

4. Cuando para evitar la consumación de un hecho o para facilitar su persecución penal, resultare idóneo prescindir de la persecución de otro hecho o de una contribución al mismo hecho, o limitar la pretensión punitiva a una pena o calificación más leve de la que

4 Código Procesal Penal Modelo para Iberoamérica Ver online: http://www.comisionreformapenal.com/wp- content/ uploads/2014/06/CODIGO-PROCESAL-PENAL-MODELO-PARA-IBEROAMERICA.pdf [09/01/16] 
efectivamente corresponde. En este último caso, no procederá la clausura del procedimiento. Esta disposición no será aplicable a hechos cometidos por funcionarios públicos en ejercicio de su cargo.

5.Cuando alguna de varias infracciones legales, que han sido cometidos por una misma acción o por varias acciones, carecen de importancia en consideración a la pena o medida de seguridad y corrección ya ejecutoriada o a la que probablemente se aplicará, se podrá limitar la persecución a la otra u otras infracciones restantes; de la misma manera se procederá cuando la pena o medida de seguridad y corrección que se espera por un hecho punible carece de importancia en consideración a la pena o medida de seguridad y corrección ya ejecutoriada o a la que se debe esperar en un proceso tramitado en el extranjero, y procede la extradición y entrega del imputado al país extranjero; en este mismo caso, se podrá prescindir de la extradición activa. En estos supuestos, el procedimiento podrá ser reabierto y se podrá proseguir, siendo este uno de los mayores esfuerzos"

Como se puede observar este código es uno de los mayores esfuerzos en poder adaptar a los países latinos las nuevas realidades jurídicas, en las que se busca dar tonalidades, lineamientos e instituciones propias del Derecho Anglosajón, siendo el principio de oportunidad uno de los mayores ejemplos, el cual gradualmente desde el año de creación de dicho código fue siendo adoptados por las legislaciones Latinoamericanas, generalmente como excepción al principio de legalidad.

\section{PROCEDIMIENTO DEL PRINCIPIO DE OPORTUNIDAD}

Como se ha podido observar en puntos precedentes, el fiscal en el marco de sus atribuciones interviene activamente en el acuerdo del principio de oportunidad, para poder abstenerse de ejercer la acción penal, cabe mencionar para que ello se logre será necesario seguir el procedimiento regular del principio de oportunidad, este punto de la investigación en mención resulta ser practico y para su mejor comprensión se fragmentara como se rige este procedimiento paso a paso.

Como Base legal adicionalmente al artículo 2 del Código Procesal Penal se debe tener en cuenta la Resolución N 1470-2005-MP-FN y la Resolución N² 2508-2013-MP-FN y por último la ley 30076 que modifico en el 2015 el artículo 2 del Código Procesal Penal; En observancia a todas estas normas se desarrollara el procedimiento en que se realiza en la actualidad el principio de oportunidad.

\subsection{ASPECTOS GENERALES DE SU APLICACIÓN}

En primer lugar, para poderse acoger al principio de oportunidad es necesario ver las exigencias generales del principio de oportunidad es decir las posibilidades de los delitos y personas que pueden acogerse, y las que no pueden.

a) Cuando el agente haya sido afectado gravemente por las consecuencias de su delito, culposo o doloso, siempre que este último sea reprimido con pena privativa de libertad no mayor de cuatro años, y la pena resulte innecesaria.

b) Cuando se trate de delitos que no afecten gravemente el interés público, salvo cuando el extremo mínimo de la pena sea superior a los dos años de pena privativa de la libertad, o hubieren sido cometidos por un funcionario público en ejercicio de su cargo.

c) Cuando conforme a las circunstancias del hecho y a las condiciones personales del denunciado, el Fiscal puede apreciar que concurren los supuestos atenuantes de los artículos $14^{\circ}, 15^{\circ}, 16^{\circ}, 21^{\circ}, 22^{\circ}, 25^{\circ}$ y $46^{\circ}$ del Código Penal, y se advierta que no existe ningún interés público gravemente comprometido en su persecución. No será posible cuando se trate de un delito conminado con una sanción superior a cuatro años de pena privativa de libertad o cometido por un funcionario público en el ejercicio de su cargo. 
Cabe mencionar que en casos de delitos ambientales existe también una excepción El Fiscal podrá también abstenerse de ejercer la acción penal, luego de la verificación correspondiente, en los casos en que el agente comprendido en la comisión de los delitos previstos en los artículos 307-A, 307-B, 307-C,307-D, 307-E del Código Penal, suspenda sus actividades ilícitas de modo voluntario, definitivo e indubitable, comunicando este hecho al Organismo de Evaluación y Fiscalización Ambiental mediante instrumento de fecha cierta. Si la acción penal hubiera sido promovida, se aplican, en lo pertinente, las mismas reglas establecidas en el presente artículo.

Posterior a observarse esto se debe observar los sujetos legitimados en primero el actor principal quien será el Ministerio Público, dirigido por el Fiscal en la mayor parte de ocasiones los fiscales de los despachos de decisión temprana son los legitimados para poder realizar el principio de oportunidad, luego el imputado es decir el sujeto activo que realice la conducta típica que se encuentre dentro de los parámetros del punto primigenio, luego el abogado defensor del imputado para la legalidad del mismo, el agraviado o sujeto pasivo del delito y el tercero civil responsable si lo hubiese.

\subsection{IMPEDIMENTOS DE APLICACIÓN}

El mayor impedimento que impone la normativa del principio de oportunidad es a los supuestos $b$ ) y c) no se puede aplicar el Principio de Oportunidad cuando el delito es cometido por un funcionario público en el ejercicio de su cargo, lo cual es materia de la presente tesis pues por parte del presente autor esta prohibición en cierto tipo de delitos exclusivamente el peculado culposo genera afectación a nuestro sistema procesal, específicamente la carga procesal y la efectivizacion de la reparación civil.

No procede la aplicación del principio de oportunidad cuando el imputado:

a) tiene la condición de reincidente o habitual, de conformidad con los artículos 46-B y 46-C del Código Penal.

b) sin tener la condición de reincidente o habitual, se hubiera acogido al principio de oportunidad o acuerdo reparatorio en dos ocasiones anteriores, dentro de los cinco años de su última aplicación, siempre que se trate, en todos los casos, de delitos de la misma naturaleza o que atenten contra un mismo bien jurídico.

c) sin tener la condición de reincidente o habitual, se hubiera acogido al principio de oportunidad o acuerdo reparatorio dentro de los cinco años anteriores a la comisión del último delito.

d) Sin tener la condición de reincidente o habitual, se hubiera acogido con anterioridad al principio de oportunidad o acuerdo reparatorio y no haya cumplido con reparar los daños y perjuicios ocasionados o lo establecido en el acuerdo reparatorio.

Esto según lo expresado en el artículo dos del Código Procesal Penal en estos casos, el Fiscal promueve indefectiblemente la acción penal y procede conforme a sus atribuciones, es decir continua con la acción penal y con el procesal penal propiamente dicho.

\section{LA LEGISLACIÓN COMPARADA, DIFERENCIAS ENTRE EL PRINCIPIO DE OPORTUNIDAD PLENO Y PRINCIPIO DE OPORTUNIDAD REGLADO}

El principio de oportunidad como ya se mencionó anteriormente en el Perú es un mecanismo relativamente nuevo, que genero distintas controversias, pues ello demostraba esa lucha constante entre la realidad y la doctrina, toda vez que la sociedad exigía respuestas y soluciones rápidas de los conflictos penales mínimos, cosa que en los procesos comunes es casi imposible por la gran carga procesal que existe, después de haber estudiado los conceptos y los antecedentes del 
principio de oportunidad, se debe distinguir la clasificación admitida del principio de oportunidad, de esta manera existen dos tipos de principio de oportunidad.

- El principio de oportunidad pleno

- El principio de oportunidad reglado

Se debe saber que en la legislación angloamericana el principio de oportunidad pleno es el que prevalece, esto es el también llamado principio de oportunidad libre, donde el titular de la acción penal, es decir el Ministerio Publico tiene libre disponibilidad y discrecionalidad en su ejercicio, Como un claro ejemplo a ello tenemos el sistema norteamericano donde el Fiscal puede negociar la pena y la ejecución cuando existe elevados elementos que funden una condena, esto se llama PLEA BARGAINING y el juez interviene para dilucidar los términos de la negociación como una especie de juez de garantías simplemente, por otra parte al imputado declararse culpable para evitar que un jurado intervenga y ser condenado por hecho más grave y mayor.

Por otro lado el principio de oportunidad reglado, es el tipo de principio de oportunidad que se usa en nuestro país y en Latinoamérica, en el cual se permite el principio de oportunidad, en ciertos supuestos, es decir condiciones normadas o regladas previamente en alguna norma procesal, casos específicos por los cuales se puede aplicar el principio de oportunidad, un ejemplo claro es el Perú, que en su artículo 2 del Código Procesal Penal, se dan los supuestos para poder acogerse al principio de oportunidad.

Se debe hacer mención, además que resultaría imposible para nuestro sistema amparar el principio de oportunidad plena, pues como sabemos nuestro sistema jurídico es el sistema Romano Germánico, en el cual la Ley es la fuente principal del derecho, bajo esa perspectiva nuestra justicia se basa en el principio de legalidad por el cual los delitos deben ser perseguidos y castigados de acuerdo a la ley penal.

Ahora bien, será de menester estudiar la legislación comparada en el principio de oportunidad, en países como Alemania, Argentina, España, Ecuador, Chile y Colombia.

a) ALEMANIA: Al observar el Código Procesal Alemán traducido no se pudo encontrar algo que se asemeje al principio de oportunidad propiamente dicho, pero se sabe que su antecedente más directo en dicho país es la Ley Emminger, "El Principio de Oportunidad tiene sus orígenes en este País a través de la Vargas Benavides expresa que la "Ley Emminger" del 04 de Enero de 1924 artículo 153 en virtud del cual el Ministerio Público quedó facultado a abstenerse del ejercicio de la acción penal para satisfacción de determinados presupuestos como son: a)Reparar el daño ocasionado, b)otorgar prestaciones de utilidad pública; y c) Cumplir determinadas obligaciones" de esta manera el principio de oportunidad se presenta como un opción pertinente a los problemas de carga procesal.

b) ARGENTINA: En Argentina el principio de oportunidad se encuentra regularizado por la ley 24.825, en el que su finalidad máxima es descongestionar la carga procesal, por medio de un acuerdo entre el Ministerio Público y la parte imputada, para que se pueda dar el principio de oportunidad debe existir un estricto consenso entre tanto la acción penal, la pena, la calificación y la reparación civil, la concepción argentina del principio de oportunidad es como nos lo dice Caffarela Nores, José (1996) "Es la posibilidad o atribución que tienen los órganos encargados de la promoción de la persecución penal, fundada en diversas razones de política criminal y procesal de no iniciar la acción, o de suspender provisionalmente la ya iniciada, o de limitar su extensión objetiva y subjetiva o de hacerla cesar definitivamente antes de la sentencia, aun cuando concurran las condiciones ordinarias para perseguir y castigar" (p. 8) es decir que en la legislación argentina resulta un medio claramente idóneo 
para enfrentar la carga procesal penal, el principio de oportunidad en Argentina es el principio de oportunidad reglado es decir que se rige rigurosamente por un cierto grupo de normas que regularizan su uso.

c) BOLIVIA: El principio de oportunidad en Bolivia aparece junto a su reforma procesal del año 1999, año en el que la celeridad procesal y la inmediatez era primordial en el proceso penal, es así que se incorpora el principio de oportunidad reglado, con la finalidad de seleccionar y reducir los procesos de menor afectación, buscando la satisfacción de la parte agraviada, existen dos formas previstas en su código Alvarez Teran, Roberto (2009) "Entre las formas previstas figuraban dos grandes grupos. El primero, relativo a la extinción de la acción penal y el segundo referido a la suspensión de la acción penal sujeta al cumplimiento de condiciones o reglas por parte de la persona imputada; denominado suspensión condicional del proceso" (p. 12), ambos casos contienen las mismas finalidades y el mismo objeto.

d) CHILE: El principio de oportunidad en Chile es un principio de oportunidad reglado y se encuentra amparado en nuestro país vecino en el artículo 170 del Código Procesal Penal, este solo se usa cuando los delitos sean de insignificancia, cabe mencionar que en el principio de oportunidad chileno existe un control judicial, con ciertos requisitos contemplados, como lo indicó Villagra Santander, Gastón (2009) "Se subrayó que en ningún caso el principio de oportunidades una decisión que queda sujeta al arbitrio del Ministerio Público, pues, además, está el juez de control (sic) y el derecho garantizado de la víctima" (p.36) El juez llamado a ver los principios de oportunidad son los jueces de garantías o llamados en Perú Juez de investigación Preparatoria.

e) ECUADOR: El principio de oportunidad en Ecuador nos muestra dos supuestos claros, a) Cuando el hecho constitutivo del presunto delito no compromete gravemente el interés público y tenga una pena máxima de hasta cinco años de prisión. (No afecta el interés del Estado) b) En los delitos donde por sus circunstancias el infractor sufriere daño físico grave que le imposibilite llevar una vida normal, o cuando tratándose de un delito culposo los únicos ofendidos fuesen su cónyuge, familiares comprendidos hasta el segundo grado de consanguinidad.

Es decir que el principio de oportunidad en ecuador es reglado el artículo 195 de la Constitución declara en su primer inciso que: "La Fiscalía dirigirá, de oficio o a petición de parte, la investigación pre procesal y procesal penal; durante el proceso ejercerá la acción pública con sujeción a los principios de oportunidad y mínima intervención penal, con especial atención al interés público y a los derechos de las víctimas " es decir que el proceso penal ecuatoriano es viabilizado más que a la sanción al resarcimiento de la víctima:

"La norma constitucional en referencia introduce por primera vez en el ordenamiento jurídico del Ecuador, las tesis e instituciones relacionadas a la oportunidad y la mínima intervención, como presupuestos y condiciones indispensables para que el sistema y el derecho penal funcionen de forma adecuada, eficaz y satisfactoria, en términos" (Vallejo, 2011 p. 109)

Generando un modelo tal vez más favorable a la parte agraviada, que recibe un resarcimiento o puesto como una reparación civil de forma más célere.

f) COLOMBIA: Se debe mencionar que esta es una fuente directa del principio de oportunidad para la presente tesis pues si bien el principio de oportunidad en Colombia es reglado, da muchas opciones de admitirse, esta se encuentra amparado en la Ley 906 del Código de Procedimientos penales, siendo el principio de oportunidad algo muy trascendente e su país pues en la Constitución Política se hace referencia de ello en su artículo 250 "La Fiscalía 
General de la Nación está obligada a adelantar el ejercicio de la acción penal y realizar la investigación de los hechos que revistan las características de un delito que lleguen a su conocimiento por medio de denuncia, petición especial, querella o de oficio, siempre y cuando medien suficientes motivos y circunstancias fácticas que indiquen la posible existencia del mismo. No podrá, en consecuencia, suspender, interrumpir o renunciar a la persecución penal, salvo en los casos que establezca la ley para la aplicación del Principio de Oportunidad.

El título V del Libro II del mencionado Código habla enteramente sobre el principio de oportunidad, iniciando textualmente, la aplicación del principio de oportunidad deberá hacerse en sujeción a la política criminal del Estado, de esta manera el articulo 324 nos otorga las causales del principio de oportunidad.

ARTíCULO 324. CAUSALES. El principio de oportunidad se aplicará en los siguientes casos:

1. Cuando se trate de delito sancionado con pena privativa de la libertad que no exceda en su máximo de seis (6) años y se haya reparado integralmente a la víctima, de conocerse esta, y además, pueda determinarse de manera objetiva la ausencia o decadencia del interés del Estado en el ejercicio de la correspondiente acción penal.

2. Cuando la persona fuere entregada en extradición a causa de la misma conducta punible.

3. Cuando la persona fuere entregada a la Corte Penal Internacional a causa de la misma conducta punible. Tratándose de otra conducta punible solo procede la suspensión o la interrupción de la persecución penal.

4. Cuando la persona fuere entregada en extradición a causa de otra conducta punible y la sanción a la que pudiera llevar la persecución en

Colombia carezca de importancia al lado de la sanción que le hubiera sido impuesta con efectos de cosa juzgada contra él en el extranjero.

5. Cuando el imputado colabore eficazmente para evitar que continúe el delito o se realicen otros, o aporte información esencial para la desarticulación de bandas de delincuencia organizada.

6. Cuando el imputado sirva como testigo principal de cargo contra los demás intervinientes, y su declaración en la causa contra ellos se haga bajo inmunidad total o parcial. En este caso los efectos de la aplicación del principio de oportunidad serán revocados si la persona beneficiada con el mismo incumple con la obligación que la motivó.

7. Cuando el imputado haya sufrido, a consecuencia de la conducta culposa, daño físico o moral grave que haga desproporcionada la aplicación de una sanción o implique desconocimiento del principio de humanización de la sanción punitiva.

8. Cuando proceda la suspensión del procedimiento a prueba en el marco de la justicia restaurativa y como consecuencia de este se cumpla con las condiciones impuestas.

9. Cuando la realización del procedimiento implique riesgo o amenaza graves a la seguridad exterior del Estado.

10. Cuando en atentados contra bienes jurídicos de la administración pública o recta impartición de justicia, la afectación al bien jurídico funcional resulte poco significativa y la infracción al deber funcional tenga o haya tenido como respuesta adecuada el reproche y la sanción disciplinarios.

11. Cuando en delitos contra el patrimonio económico, el objeto material se encuentre en tan alto grado de deterioro respecto de su titular, que la genérica protección brindada por la ley haga más costos asu persecución penal y comporte un reducido y aleatorio beneficio.

12. Cuando la imputación subjetiva sea culposa y los factores que la determinan califiquen la conducta como de mermada significación jurídica y social.

13. Cuando el juicio de reproche de culpabilidad sea de tan secundaria consideración que haga de la sanción penal una respuesta innecesaria y sin utilidad social.

14. Cuando se afecten mínimamente bienes colectivos, siempre y cuando se dé la reparación integral y pueda deducirse que el hecho no volverá a presentarse. 
15. Cuando la persecución penal de un delito comporte problemas sociales más significativos, siempre y cuando exista y se produzca una solución alternativa adecuada a los intereses de las víctimas.

16. Cuando la persecución penal del delito cometido por el imputado, como autor o partícipe, dificulte, obstaculice o impida al titular de la acción orientar sus esfuerzos de investigación hacia hechos delictivos de mayor relevancia o trascendencia para la sociedad, cometidos por él mismo o por otras personas.

17. Cuando los condicionamientos fácticos o síquicos de la conducta permitan considerar el exceso en la justificante como representativo de menor valor jurídico o social por explicarse el mismo en la culpa.

De esta manera nos centraremos en el punto 10 que nos dice 10. Cuando en atentados contra bienes jurídicos de la administración pública o recta impartición de justicia, la afectación al bien jurídico funcional resulte poco significativa y la infracción al deber funcional tenga o haya tenido como respuesta adecuada el reproche y la sanción disciplinarios.

En relación a este punto se analizara que se entiende por afectación al bien jurídico funcional debe ser poco significativa y la infracción del deber funcional tenga o haya tenido como respuesta adecuada el reproche institucional y la sanción disciplinaria correspondiente; En relación a la primera es debatible poder comprenderla en todo su concepción pues las políticas criminales actuales buscan siempre las máximas sanciones para los delitos de corrupción de funcionarios por el deber especial que ellos cuentan, es así que al respecto de dicha causa su tribunal Constitucional ya se pronunció, en la Sentencia C-988 de 2006, expresó que la aplicación de la causal está supeditada, entre otras cosas, a que la afectación del bien jurídico resulte poco significativa, "es decir, que la afectación de la administración pública o de la eficaz y recta impartición de justicia sea leve, valoración que deberá efectuar en concreto la Fiscalía, el Juez de Garantías encargado de realizar el respectivo análisis de antijuridicidad y proporcionalidad con ocasión del control de legalidad respectivo". Como segundo punto este debemos dividirlo en tres qué se entiende por deber funcional, he aquí don se ingresa al ámbito de la infracción de deberes en los delitos contra la administración pública, por otra parte la respuesta disciplinaria como fundamento de aplicación de la causal, se consagra en las respuestas estatales no penales y en qué debe consistirla respuesta disciplinaria?, esta se entiende como una sanción administrativa disciplinario, un despido, memorándums entre otros según sea la gravedad del hecho, cabe mencionar que el extraneus no es susceptible a dicho principio de oportunidad toda vez, que la propia norma habla de deberes funcionales que radican específicamente en los funcionarios públicos.

\section{METODOLOGÍA}

La investigación es descriptiva, con carácter exploratorio, perteneciente al área socio- jurídica, la fuente o el origen de la investigación, es empíricas de corte transversal al estudiar datos de la realidad específicamente de los Expedientes judiciales. El método utilizado es el inductivo-deductivo de manera general, y el analítico- interpretativo a partir del análisis estadístico. Utilizándose de muestra las investigaciones de la procuraduría publica anticorrupción en Tacna entre los años 2010 al año 2015, dándole mayor énfasis al delito de peculado culposo.

La información necesaria para el desarrollo de la investigación se recopilo mediante técnica de análisis documentario. El análisis documentario es de sentencias de primera instancia emitidas en la Corte Superior de Tacna, además de Disposiciones de la Fiscalia Publica Anticorrupcion de Tacna, específicamente para poder Determinar si la prohibición del principio de oportunidad en los Delitos de Peculado Culposo incide significativamente en la congestionada carga procesal de la Fiscalía Especializada en Delitos de Corrupción de Funcionarios y la Procuraduría Pública Anticorrupción, impidiendo el pago de la reparación civil de forma célere, en Tacna en los años del 2010 al 2015, en merito a la carga procesal que existió en el año 2015. 


\section{CUADRO $N^{\circ} 1$}

CARGA PROCESAL NUMÉRICA DE LA PROCURADURÍA Y FISCALÍA ESPECIALIZADA EN DELITOS DE CORRUPCIÓN EN EL AÑO 2015

\begin{tabular}{|c|c|}
\hline PROCESOS DE DELITOS DE CORRUPCIÓN & PROCESOS DE PECULADO CULPOSO \\
DE FUNCIONARIOS SEGUIDOS POR LA & SEGUIDOS POR LA FEDCF DE TACNA Y LA \\
FEDCF DE TACNA Y LA PPAD DE TACNA EN & PPAD DE TACNA EN LOS AÑOS \\
LOS AÑOS 2010 AL 2015 & 2010 AL 2015 \\
\hline 465 & 38 \\
\hline
\end{tabular}

\section{GRÁFICO No 1}

NÚMERO DE CASOS A FINALES DEL 2015

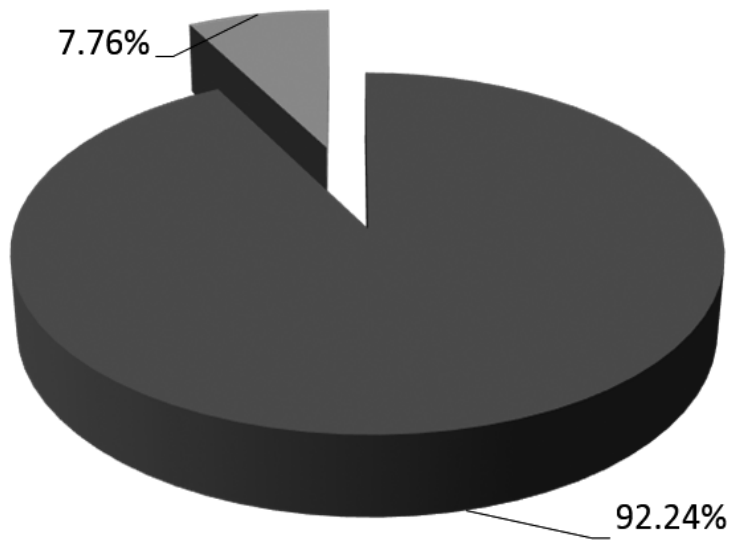

Casos en giro al 2015

- Casos en giro de peculado culposo

\section{RESULTADOS}

\section{Sobre el tiempo de demora de un proceso penal hasta lograr la sentencia en delitos de} corrupción

El presente grafico se observará el lapso de tiempo en años que demora un proceso penal solo en la etapa judicial, lográndose determinar que los procesos penales de delitos de corrupción de funcionarios en su mayor parte son muy amplios pues demoran entre 7 a 10 años, seguido por de 4 a 6 años, existiendo un número considerable que tarda entre 11 a 14 años, siendo un plazo excesivo para poder lograr una sentencia.

\section{Tiempo que demora un proceso hasta la} sentencia condenatoria

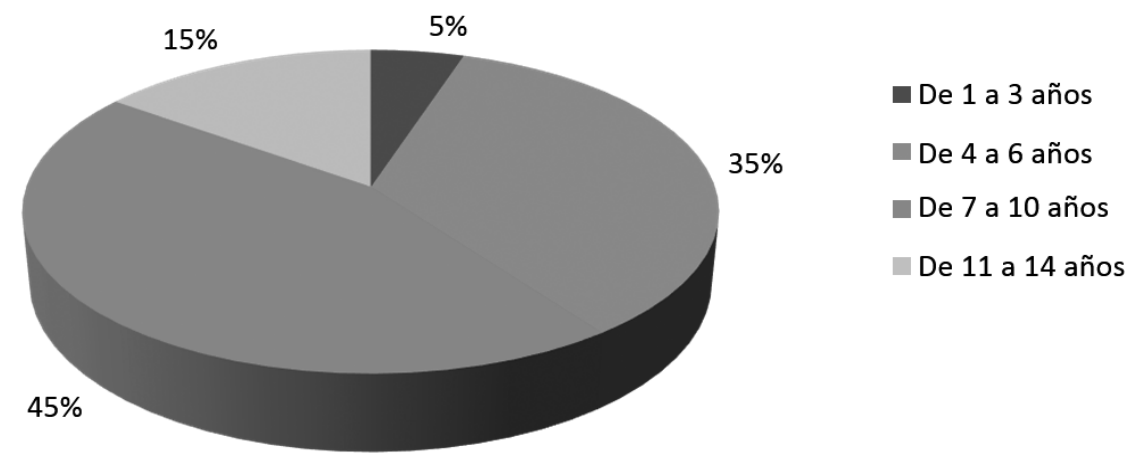




\section{Sobre la efectivización del pago de la reparación civil}

Ahora bien, en relación a la efectivizacion de la reparación civil a favor del Estado cuando se da sentencia condenatoria, observamos que existe un $75 \%$ que aún no paga su respectiva reparación civil, que fue emitida en su sentencia, siendo claro, que al existir una sentencia condenatoria, la parte imputada olvida su responsabilidad civil, existiendo un mínimo estímulo para el pago de reparación civil de forma célere.

\section{Efectivización del pago de la reparación civil en las sentencias condenatorias}

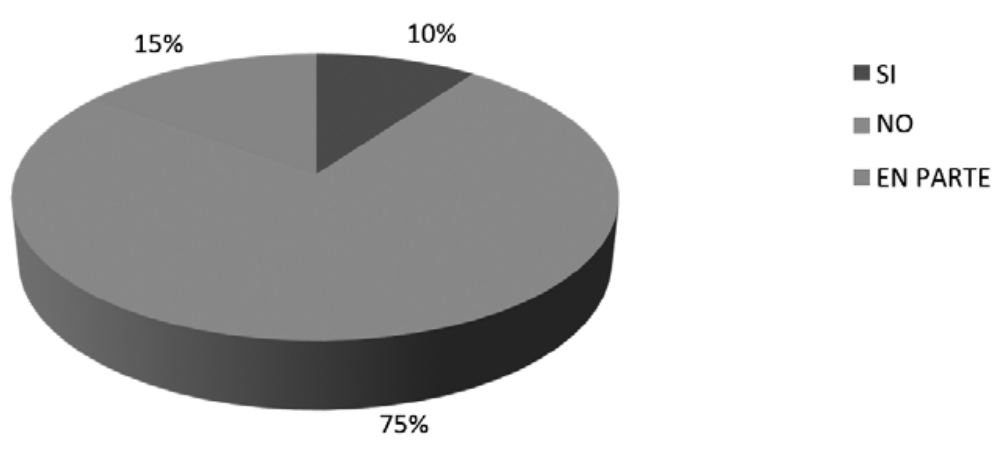

\section{Delitos con sentencia condenatoria en corrupción de funcionarios}

En el presente cuadro se distingue claramente que los delitos de resultado como son el peculado y sus distintas modalidades son los que más llegan a sentencia, no solo por ser el tipo penal con más procesos, sino también por llegar a ser más fácil su probanza a comparación de otros tipos penales de corrupción de funcionarios, el peculado en el presente cuadro contiene un $80 \%$ de todas las sentencias.

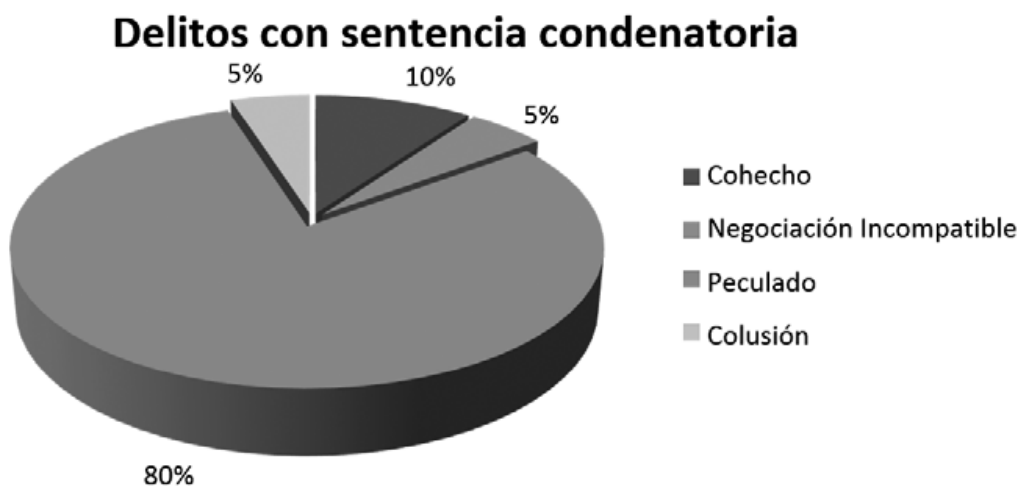

4. Sobre el tiempo de demora en un proceso penal en corrupción al usar la conclusión anticipada

El presente grafico nos muestra el lapso de tiempo en años que demora un proceso penal hasta lograr una conclusión anticipada del proceso, lográndose determinar que la conclusión anticipada de delitos de corrupción de funcionarios en su mayor parte es considerablemente rápida pues por lo general en un $80 \%$ de los casos dura entre 3 a 4 años, siendo un tiempo razonable para lograr sentencia, teniendo en cuenta que los procesos por corrupción de funcionarios son en la mayor parte complejos. 
Tiempo en el que demora un proceso por conclusión anticipada

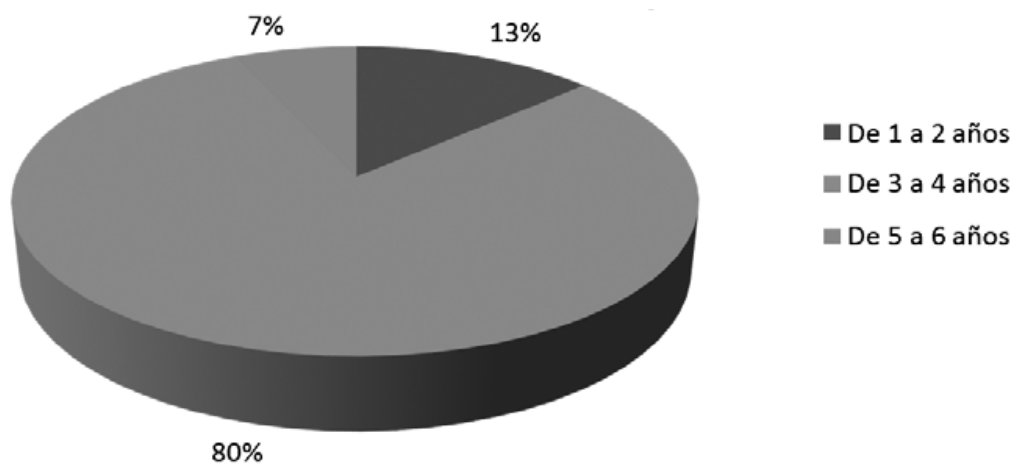

5. Sobre la efectivización del pago de la reparación civil en las conclusiones anticipadas

Ahora bien, en relación a la efectivizacion de la reparación civil a favor del Estado cuando se da sentencia condenatoria, observamos que existe un $60 \%$ que pago en parte su reparación civil, por otra parte un $40 \%$ que ya concluyo el pago de la reparación civil a favor del Estado, existiendo un claro estimulo del pago de la reparación civil.

\section{Efectivización de la reparación civil en la conclusión anticipada}

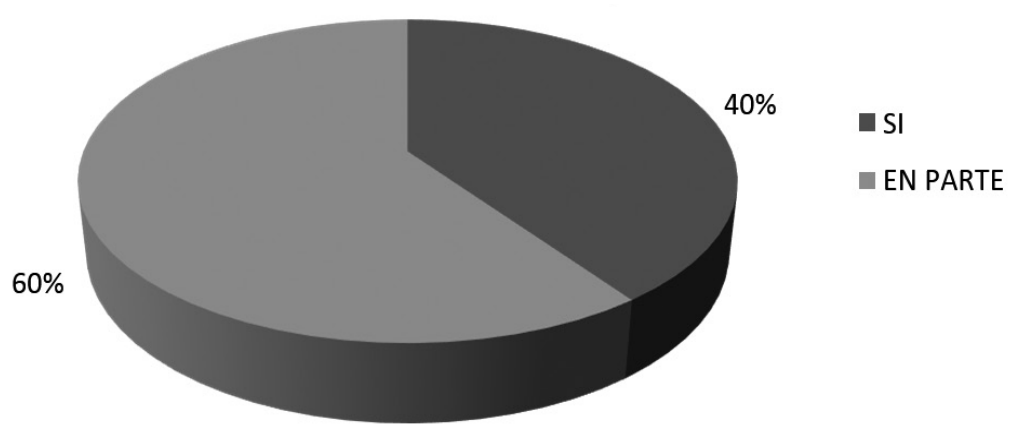

6. Sobre el tiempo de demora en un proceso de corrupción al acogerse a la terminación anticipada

El presente grafico nos muestra el lapso de tiempo en años que demora un proceso penal hasta lograr una terminación anticipada del proceso, lográndose determinar que la conclusión anticipada de delitos de corrupción de funcionarios en su mayor parte son realmente rápidos pues por los general en un $50 \%$ de los casos dura 1 año en estadio judicial, con otro $50 \%$ que dura 2 años en estadio judicial, siendo un tiempo célere para la obtención de una reparación civil y disminución de la carga procesal.

Tiempo que demora un proceso por terminación anticipada

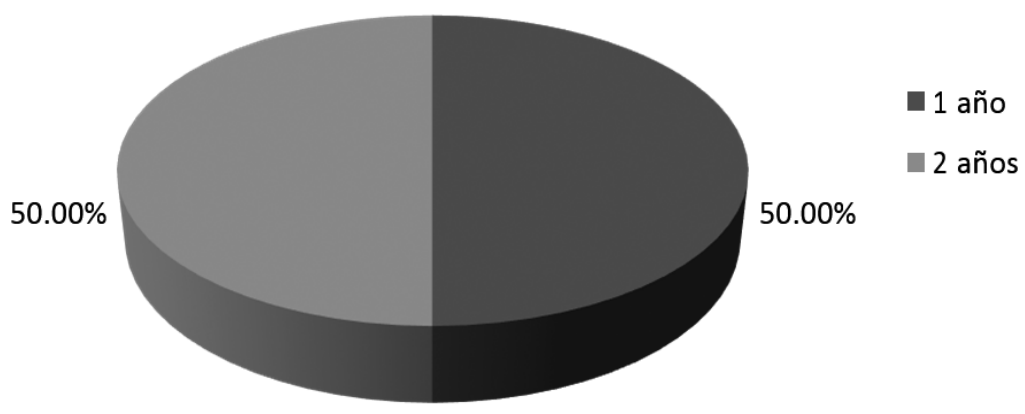




\section{Sobre la efectivización del pago de la reparación civil en terminaciones anticipadas}

Ahora bien, en relación a la efectivizacion de la reparación civil a favor del Estado cuando se da sentencia condenatoria, observamos que existe un $50 \%$ que ya pago totalmente su reparación civil a favor del Estado, por otra parte existe otro $50 \%$ que ha pagado solo en parte, existiendo mayor índice de pago de la reparación civil a favor del Estado, siendo este mecanismo alternativo de solución, uno de los más idóneos para poder obtener de forma célere la reparación civil.

\section{Efectivización del pago de las reparaciones civiles en terminación anticipada}

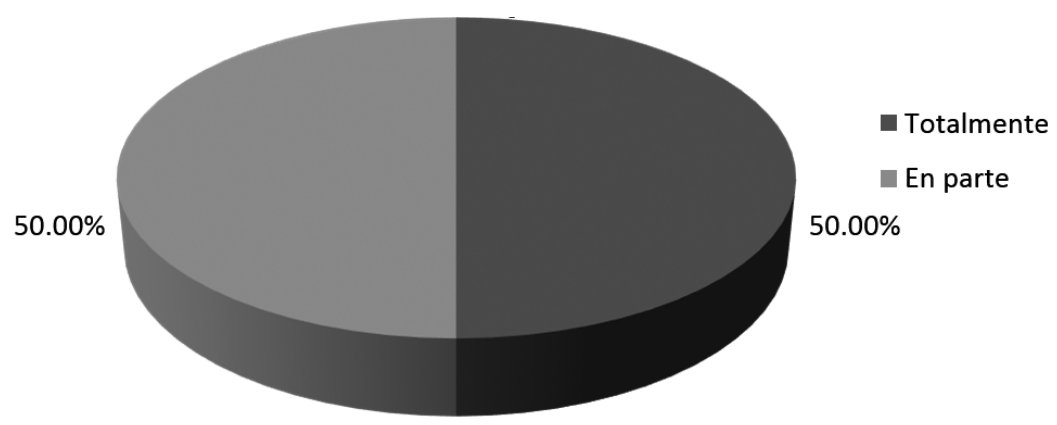

\section{CONCLUSIONES}

PRIMERA. - Si bien los casos de peculado culposo no comprenden la mayoría de la carga procesal en la Fiscalía Especializada en Delitos de Corrupción de Funcionarios y la Procuraduría Anticorrupción, esta carga si incide significativamente a nivel nacional en la ya comprobada congestionada carga de estas instituciones, pues una disminución de alguna manera colaboraría con la mejora administrativa y procesal de aquellas, colaborando enormemente a mejorar su desempeño.

SEGUNDA. - Los mecanismos alternativos de solución de conflictos penales son la mejor vía al pago efectivo y de forma célere de la reparación civil a favor del Estado, y restringiendo una posibilidad como está, a un delito en el cual el bien jurídico protegido es mínimo y los costos procesales son altos, se impide el pago de una reparación civil de forma célere, generando costos más que beneficios, a un sistema procesal ya sobrecargado.

TERCERA.- El artículo 2 del Código Procesal Penal en relación al principio de oportunidad es limitativo para descongestionar la carga procesal y ser más eficiente en la persecución de los delitos contra la administración pública en general, pues al prohibirse este mecanismo alternativo de solución de conflictos penal en los delitos cometidos por funcionarios, específicamente el delito de peculado culposo se está generando una excesiva carga procesal innecesaria a las instituciones públicas relacionadas a este tipo de delitos, además de impedir el pago de una reparación civil de forma célere a favor del Estado, es por ello que se requiere una modificación con suma urgencia, para poder seguir progresando en el plan nacional anticorrupción que se realiza paulatinamente todos los años para la mejora del tratamiento en estos delitos.

\section{REFERENCIAS BIBLIOGRÁFICAS}

- Alvarez, R. (2009) Principio de oportunidad en los delitos contra la administración pública en Bolivia, Universidad de Salamanca.

- Bacigalupo, E. (1987) Descriminalización y prevención, Revista del Poder Judicial, Numero Especial II. 
- Caffarela, J. (1996) El principio de oportunidad en el derecho argentino, teoría, realidad y perspectiva en Nueva doctrina penal, Editorial Del Puerto, Buenos Aires-Argentina.

- Catacora, C. (1996) Derecho Procesal Penal Vol. I, Editorial RHODAS, Lima-Perú.

- Martinez, M. (ED) (2015) Tratado de los Delitos y de las penas de Cesare Beccaria, Madrid, España: Editorial Universidad III de Madrid ISBN: 978-84-89315-76-1 Recuperado de: http:// hdl.handle.net/10016/20199

- Gongora, M. El principio de Oportunidad en el Código de Procedimiento Penal de Colombia, Ver Online: En el Centro de Derechos Humanos NurnbergerMenschenschtszentrum NMRZ; Recuperado de: http://www.menschenrechte.org/lang/es/lateinamerika/oportunidadprocedimiento-penal- colombia>

- Nereu, G. (2012) Legalidad, oportunidad y consenso en el Derecho Penal, Editorial ARA, Lima-peru, año 2012.

- Prado, V. (1990); Derecho Penal y Política, Lima-Perú: Editorial EDILI p. 84

- Vallejo, S. (2011) Las salidas alternativas como medio para dar por terminado el proceso penal, contempladas en nuestra legislación vigente, Universidad de Cuenca, Cuenca- Ecuador.

- Vargas, R. (s.f.) El principio de oportunidad. Recuperado de: https://www.pj.gob.pe/wps/wcm/ connect/80c6790046e0f63e89f48944013c2be7/Tema+II.pdf

- ?MOD=AJPERES\&CACHEID=80c6790046e0f63e89f48944013c2be7

- Villagra, G. (2009) El control judicial y administrativo del principio de oportunidad, la facultad de no iniciar la investigación y el archivo provisional en el proceso penal, Universidad de Chile, Santiago-Chile.

Fecha de recepción: 23 de octubre de 2020

Fecha de aceptación:06 de noviembre de 2020 